\title{
ENTREVISTA \\ História e historiadores: entrevista com Lucília de Almeida Neves Delgado
}

\section{INTERVIEW}

History and historians: inteview with Lucília de Almeida Neves Delgado

\author{
Euclides de Freitas Couto* \\ Marcelo Cedro
}

\begin{abstract}
Contar é muito dificultoso. Não pelos anos que já se passaram. Mas pela acústica que têm certas coisas passadas de fazer balance, de se remexerem dos lugares. A lembrança da vida da gente se guarda em trechos diversos; uns com os outros acho que nem se misturam. Contar seguido, alinhavado, só mesmo sendo coisas de rasa importância. Tem horas antigas que ficaram muito mais perto da gente do que outras de recente data. Toda saudade é uma espécie de velhice (Guimarães Rosa).
\end{abstract}

Nesta entrevista, apresentamos a historiadora Lucília de Almeida Neves Delgado, que possui vasta carreira acadêmica nas diversas instituições de ensino superior, na qual esteve e ainda está vinculada. Natural da cidade mineira de São João del Rei, podemos destacar suas atuações como docente, pesquisadora e orientadora nos cursos de graduação e pós-graduação na Pontifícia Universidade Católica de Minas Gerais (PUC Minas), Universidade Federal de Minas Gerais (UFMG) e Universidade de Brasília (UNb). Também exerceu funções administrativas, consultivas e de gestão frente à Pró-Reitoria de graduação da UFMG; à Coordenação de Aperfeiçoamento de Pessoal de Nível Superior (CAPES), à Associação Brasileira de História Oral (ABHO), ao Conselho Nacional de Desenvolvimento Científico e Tecnológico $(\mathrm{CNPq})$, à Fundação de Amparo à Pesquisa do Estado de São Paulo (FAPESP), à Fundação de Amparo à Pesquisa do Estado de Minas Gerais (FAPEMIG), à Associação Nacional de História (ANPUH), dentre outros vínculos e atividades institucionais.

\footnotetext{
* Pós-doutorando pela Universidade Federal do Rio de Janeiro (UFRJ), Doutor em História pela Universidade Federal de Minas Gerais (UFMG), Professor da Universidade Federal de São João del Rei (UFSJ)

${ }^{* *}$ Historiador, Doutor em Ciências Sociais (PUC Minas). Professor do Departamento de História da PUC Minas.
} 
Lucília Neves Delgado produziu inúmeros trabalhos dialogando com as interfaces da História e outras áreas acadêmicas, sobretudo, com a Ciência Política. Há de se destacar sua intensa formação humanista e seu trânsito interdisciplinar com as Ciências Sociais e com a Literatura, sem, contudo, abrir mão da perspectiva histórica ancorada na memória e permeada pela intensa dedicação aos estudos acerca da oralidade. Nesse sentido, compartilhamos com os leitores da revista Cadernos de História, o rememorar de sua trajetória nessa rica entrevista que nos foi gentilmente concedida para integrar ao dossiê História e Historiadores.

\section{Prof ${ }^{a}$ Lucília, fale-nos a respeito da sua trajetória desde os tempos da graduação e de como o seu trânsito formativo, construído entre a História e a Ciência Política, impactaram na sua formação intelectual?}

Muito obrigada pela oportunidade de falar a vocês e aos leitores do Cadernos de História da PUC Minas sobre a minha trajetória como historiadora. Sou-lhes muito grata, pois essa é uma oportunidade de, com os olhos do presente, rever a construção de meu trânsito acadêmico que se deu em uma pluralidade de vias e locais. Além disso, responder às indagações propostas estimula-me a visitar o passado e, sobre ele, refletir sob uma perspectiva holística. Trata-se, enfim, de uma rica oportunidade de dialogar com minha própria memória e de me reconhecer em cada detalhe do que, aqui, narrarei.

Penso que tive uma trajetória plena de desafios. Trajetória que me alimentou de energia e, sobretudo, de alegrias colhidas, em especial, no exercício do magistério e no contato cotidiano com alunos. Eles são o esteio e razão maior do esforço, dedicação, prazer e realização dos profissionais que se dedicam ao magistério. Aos meus exestudantes, ofereço estas reflexões, em forma de lembranças, pois, como diz Rubem Alves, em seu livro, Sete vezes Rubem, foram eles os responsáveis pela prática do magistério. Alunos que puderem revelar minha alma.

Minha formação como historiadora antecipa alguns anos o curso de graduação. No antigo ginásio, no Colégio Stella Matutina, em Juiz de Fora, tive duas professoras de História e Geografia que eram irmãs. As senhoras, Albertina e Henriqueta Simões, despertaram, em mim, o gosto pelo estudo das humanidades. Suas aulas, ainda que à moda antiga, eram ricas em informações e conseguiram apresentar, com muito sabor, os fluxos temporais e espaciais em sua historicidade. 
Nessa fase, entre 14 e 15 anos, também frequentei a Juventude Estudantil Católica (JEC) sob a orientação do frei dominicano Hilton Japiassu, um grande filósofo e amigo, colhido pela morte há poucos anos. Todos os sábados, estudávamos textos de pensadores como Theilhard de Chardin e Michel Quoist. Embora algumas dessas leituras, em especial as de Chardin, estivessem, por vezes, um pouco além do meu entendimento, estimularam-me a analisar e a pensar, o que é vital para o exercício do ofício de historiador.

Mais adiante, ao final do ensino médio e início do ensino universitário, participei de grupos de estudo sobre marxismo. Visitei, juntamente com outros jovens, o pensamento de Marx, Engels, Luckács, Lenin e finalmente Gramsci, que se tornou o pensador que, com seus conceitos de hegemonia e sociedade civil, mais influenciou a redação de minha tese de doutorado sobre trabalhismo no Brasil, anos depois, na Universidade de São Paulo.

Retornando à sequência da minha formação estudantil, ao me preparar para o vestibular, tive a sorte de contar com alguns professores da área de humanidades, que faziam de suas aulas lições de erudição, cultura e reflexão. Com carinho e admiração recordo-me sempre de José Paulo Neto, grande teórico marxiniano e, hoje, professor emérito da UFRJ. Gilvan Pereira, que era muito culto e oferecia aulas estimulantes. Flora Mattos, que me levou, com competência ímpar e dedicação prazerosa, a viajar, com enorme curiosidade, e efetiva concentração, pelos extensos campos da Geografia. Com alegria, assistia às suas aulas, pois elas me desafiavam. Por fim, Nilo Camilo Ayupe que ministrava inesquecíveis lições de Português. Com o Professor Nilo, um protestante da melhor cepa, encontrei-me no terceiro ano do curso clássico do Instituto Grambery, também em Juiz de Fora. Ele insistia, quase que diariamente, para que eu fizesse vestibular para Letras. Embora minha maior paixão seja a História, acho que ele não deixava de ter razão, pois meu gosto pela Literatura, à qual me dedico, intensamente, como leiga, só cresceu e se aprofundou ao longo dos anos.

Hoje, tenho oportunidade de participar de um clube de leitura aqui em Brasília, coordenado por minha xará Lucília do Carmo Garcez, professora aposentada de Linguística da UnB, que se dedica à literatura infantil. São reuniões mensais, com debate franco e estimulante sobre diferentes livros e autores das literaturas nacional e internacional. Tenho aprendido muito e o prazer de participar dessas reuniões é inigualável. 
Na graduação, também encontrei excepcionais professores. Foi na Universidade Federal de Juiz de Fora (UFJF) que minha formação ganhou uma de suas marcas definitivas. Cursei História nos anos de 1971 a 1974. Aquele foi o tempo mais duro da ditadura que derrubou o presidente constitucional João Goulart, em 1964. Tínhamos um medo cotidiano que contaminava a sala de aula e as relações interpessoais. Naquela época, olhávamos desconfiados e com temor para pessoas que pensávamos podiam ser agentes das forças de segurança, infiltrados na universidade. Os anos eram mesmos de chumbo e a área das humanidades era especialmente visada. Mas, apesar das circunstâncias, tive uma formação estruturalista sólida. Refiro-me ao estruturalismo marxiniano, que até hoje não entendo como, conseguiu ser a marca de muitas de nossas aulas e debates acadêmicos naquele tempo de censura e repressão.

Alguns professores marcaram profundamente minha vida universitária. Destacarei dois que, para mim, foram essenciais. José Francisco Simões, irmão das minhas duas professoras do curso ginasial, transitava, com denso conhecimento, pelas diferentes correntes filosóficas da história da humanidade e por seus pensadores. Fui sua aluna de História da Filosofia de I a V. Naveguei, ainda que de forma horizontal, nas estimulantes aulas sobre o pensamento de grandes filósofos como Sócrates, Platão, Tomás de Aquino, Maquiavel, Espinosa, Hobbes, Locke, Voltaire, Rousseau, Tocqueville, Marx, Engels e Weber. Suas aulas contribuíram para que eu tivesse uma formação clássica, hoje, usualmente ausente dos bancos universitários e das grades curriculares dos cursos de História, o que considero um forte equívoco. A base analítica e o rigor que ele impunha aos encontros estão presentes em mim como chama viva que nunca se apagou. Muito facilitaram meu mergulho na Ciência Política (mestrado e doutorado) e muito contribuíram para meu preparo para a docência. Raramente se encontram professores com a densidade de Simões, por isso a sua lembrança é, para mim, permeada pela gratidão.

A outra referência, de importância ímpar, foi Vera Lúcia Costa de Melo Reis, de quem fui monitora. Já tinha sido minha professora no ensino médio. A opção que eu vinha amadurecendo de cursar História consolidou-se quando assisti às suas aulas. Estava, então, no segundo ano do curso científico da Fundação Educacional Machado Sobrinho e tinha entre 16 e 17 anos de idade. Na UFJF, seu desempenho, ao ministrar as disciplinas História Econômica I e II, era brilhante. As leituras por ela indicadas, como 
Maurice Doob, Paul Sweezy, autores marxianos ${ }^{1}$, foram fundamentais na minha formação e em sua consolidação em muitos e sequentes anos de estudo diário. Vera foi uma mestra excepcional. Dona de uma didática inovadora - que muito estimulava aos jovens naquela época era dinâmica, competente, muito exigente, mas, sobremaneira, afável e afetuosa. Em suas aulas, bem como nas atividades de monitoria, muito aprendi como ser professora, como estudar, ter disciplina acadêmica, determinação, o gosto pelo conhecimento profundo, além de ter sempre muito respeito e carinho para com os alunos. Os conhecimentos da professora Vera moram em mim como uma força inquestionável, mesmo após 43 anos de conclusão da minha graduação.

Penso que, naqueles anos inaugurais, que são sempre definidores da trajetória, ao conviver em profundidade com católicos, marxistas e protestantes, em mim, ganhou força, ainda que de forma inconsciente, um respeito profundo pelas diferenças. Sou grata por ter conseguido, na minha vida pessoal, que se entranha na vida profissional, ter cultivado esse valor. Ele foi e é essencial para mim.

Finalmente, um ano após concluir a graduação e já ter abraçado o magistério em cursinhos supletivos, pré-vestibulares e nos ensinos básico e médio, decidi que deveria cursar um mestrado. A opção recaiu na Ciência Política e na Universidade Federal de Minas Gerais. Foi uma pequena curva na minha formação e uma guinada na minha vida. Mas não me senti despreparada para enfrentar o dia a dia de estudos na pós-graduação devido aos anos de estudos anteriores. Foi uma temporada desafiante e muito estimulante que incluiu a mudança de Juiz de Fora para Belo Horizonte. Era hora de voar, fazer novos amigos e participar de inúmeros debates acadêmicos. Foi nessa fase que defini um conceito sobre conhecimento humanista que, até hoje, orienta meus atos. Sem qualquer preconceito para com as áreas das Ciências Exatas, que navegam em outros mares, entendo que o conhecimento jamais é exato, cartesiano. Ele não se constrói na superfície e com base em um único parâmetro. Sua elaboração e consolidação acontecem na profundidade, na reflexão crítica e tem múltiplos parâmetros a orientá-lo. Suas chamas são muitas e, somente em conjunto, conseguem iluminar, com algum contento, a realidade.

Naqueles anos, estávamos na metade da década de 1970 e os estudos e pesquisas sobre os movimentos operário e sociais pululavam nas universidades. Como filha do

\footnotetext{
${ }^{1}$ O termo marxiano refere-se a autores que utilizam o pensamento de Marx em suas análises sem, contudo, serem adeptos de uma ortodoxia pouco permeável. Já o termo marxista refere-se a pensadores vinculados a uma tradição ortodoxa.
} 
meu tempo, a opção por escrever uma dissertação sobre o Comando Geral dos Trabalhadores (CGT) que, atuou entre 1961 e 1964 no Brasil, foi feita com absoluta naturalidade. Favoreceu essa escolha, minha história em Juiz de Fora, onde ouvira notícias sobre Clodesmidt Riani que foi presidente do $\mathrm{CGT}^{2}$. As aulas do cientista político, Luís Werneck Vianna, que acabara de publicar uma obra que se tornou clássica, Liberalismo e Sindicato no Brasil, também me estimularam. Marxiniano por formação e convicção, Werneck Vianna, com toda a densidade que lhe é peculiar, foi um professor exigente que se tornou amigo para toda uma vida.

O orientador da dissertação foi Michel Marie Le Ven, que tinha sólida formação religiosa católica. Antes de ingressar na academia, foi padre operário. Tinha também um gosto especial pelas pesquisas sobre trabalho humano e movimentos sociais. Com ele, construí uma parceria afetiva e acadêmica que se consolidou em sólida amizade e se desdobrou em pesquisas compartilhadas após ter me tornado professora dos departamentos de Ciência Política e História da UFMG. A banca que avaliou minha dissertação foi formada por: Michel Marie Le Ven, Luiz Werneck Vianna e Antônio Fernando Mitre.

A continuidade da formação na pós-graduação teve sequência com o doutorado, cursado na USP, na década de 1980. Lá encontrei um ambiente com forte tradição universitária, no qual o debate acadêmico era a tônica. Cursei disciplinas sobre teoria política com Francisco Weffort, movimentos sociais com Ruth Cardoso e movimento operário com Leôncio Martins Rodrigues, entre outras. Leôncio Martins Rodrigues foi meu orientador. Aliás, grande professor e orientador! Foram muitos os autores que lemos para os seminários da sua disciplina. Entre eles: José Albertino Rodrigues, Maria Hermínia Tavares de Almeida, Azis Simão, o próprio Leôncio Martins Rodrigues, Kenneth Erickson e Phillip C. Schmitter. Mas, além das leituras e férteis discussões, na convivência acadêmica com ele, aprendi como orientar. Leôncio Martins Rodrigues é um dos maiores estudiosos do Brasil, com sólido reconhecimento internacional sobre o mundo do trabalho. Ser sua orientanda foi um feito que considerei à época inacreditável. Muito lhe agradeço, pois entendo que a gratidão é a memória do coração.

\footnotetext{
${ }^{2}$ Com treze anos registrei, no meu diário de adolescente, um comentário sobre o sindicalista Clodesmidt Riani. Eu o ouvira em minha casa quando meu pai, General Roberto de Almeida Neves, conversava com amigos sobre como apoiar a numerosa família de Riani, que era preso político. Eles diziam que seria melhor conseguir emprego para os filhos mais velhos, por ser mais digno, e não simplesmente entregar à família gêneros alimentícios. Foi um estímulo histórico e uma lição de vida sobre generosidade e respeito à dignidade humana.
} 
A tese sobre o Partido Trabalhista Brasileiro (1945 a 1964) foi sustentada por uma pesquisa documental e bibliográfica exaustiva que cheguei a pensar, nunca mais acabaria. Na USP, as defesas de dissertação e de tese recebem notas e tive a grata alegria de receber a nota dez com louvor, por unanimidade de uma banca formada por: Leôncio Martins Rodrigues, Maria Vitória Benevides, Angela de Castro Gomes, Régis de Castro Andrade e Eduardo Kulgemas. Depois de defendidas, foi com grande alegria que vi dissertação e tese publicadas em livros.

Os anos de doutoramento conformaram o período em que me senti mais desafiada em minha vida profissional. Era professora da Universidade Federal de Minas Gerais (UFMG). Minhas meninas, Gabriela e Marina, eram muito pequenas. Aliás, Marina era um bebê e nas viagens para São Paulo sempre levei comigo o sentimento de divisão e de culpa por minhas ausências. Sentimento que continua sendo o fantasma de milhões de mulheres. Mas passados os anos - hoje, estão adultas e penso, com justo alívio, que o espelho foi mais forte do que a ausência.

E, ao olhar as nuances da temporalidade do meu viver, tenho convicção de que, desde o tempo em que ingressei no mestrado, o que construí, ao longo dos anos subsequentes, teve não só apoio, mas a participação efetiva de meu companheiro de jornada e cúmplice de um amor que se renova há quarenta e um anos, Mauricio.

\section{Quais as principais motivações que te conduziram a trilhar a carreira acadêmica?}

Devo confessar que, quando escolhi cursar História, não tinha qualquer pretensão acadêmica. Eu tinha um imenso gosto pela área de conhecimento e pronto. Mas na medida em que minha formação universitária foi avançando, era inevitável pensar no futuro e nas possibilidades dos caminhos a percorrer.

O magistério fez parte da minha vida, desde minha matrícula, no terceiro período da faculdade. Comecei dando aulas para cursos supletivo e pré-vestibular. Quando me formei, assumi aulas em colégios onde eu havia estudado. Para o primeiro grau, no Colégio Stella Matutina, e, para o segundo grau, no Colégio Machado Sobrinho, ambos em Juiz de Fora.

Simultaneamente ao curso de graduação, trabalhei na Secretaria de Cultura da Prefeitura Municipal de Juiz de Fora, onde tive a oportunidade de exercer meu ofício no acervo histórico filmográfico. Os filmes eram documentários sobre a política nacional e o cotidiano da própria cidade de Juiz de Fora, dirigidos, com pioneirismo, pelo cineasta 
João Carriço. Hoje, para minha alegria, estão digitalizados e preservados. Foi uma experiência intensa e desafiadora. Eu nada conhecia da área de cinema, que é vasta, exige conhecimento técnico e é muito diversificada. Percebi, todavia, que aquele seria um caminho árduo, pouco valorizado e muito instável, pois dependeria sempre de financiamentos públicos ou privados. Mas foi uma experiência única que contribuiu para minha compreensão de que o cinema é uma excelente fonte para construção do conhecimento histórico. Análises e discussões sobre filmes - documentários ou ficção são sempre parte das minhas aulas.

Aquele foi um tempo de muitas realizações e expectativas difusas. Eu era muito jovem e, para além do trabalho e do estudo, abraçava o viver com imenso entusiasmo. $\mathrm{O}$ dia era curto para tanta vida: música, teatro, ida a botecos, viagens, passeios por horas a fio pelas ruas e praças de Juiz de Fora, conversas extensas com amigas e amigos - quase sempre varando as madrugadas das sextas e dos sábados -, idas ao cinema com incrível assiduidade, práticas na militância política pelo retorno da democracia, aprendizagem de técnicas rudimentares de pintura - de que sempre gostei -, carnavais antes e depois dos dias oficiais de folia e a frequência em clubes.

Meus olhos do presente, do alto dos meus 65 anos, visitam esses dias com emoção e nostalgia. Era o tempo da ditadura, mas era um tempo de muita esperança. Jamais poderia pensar que o Brasil que imaginávamos construir chegaria à quase desintegração dos dias presentes. O que temos hoje, no Brasil, é um governo ilegítimo, uma mídia uníssona, um retrocesso nos direitos sociais, uma proliferação da intolerância e de práticas patrimonialistas em graus assustadores! Muito menos poderia prever que o magistério enfrentaria desvalorização e desrespeito crescentes que afastam jovens talentosos dessa carreira. Minha utopia juvenil, hoje, se transformou em distopia. Mas professor algum pode ou deve ser pessimista, pois forma cérebros e corações para atuarem na vida prática. Esse quadro de desalento, somado a quarenta e cinco anos de intensa docência, fizeram-me concluir que é chegada a hora do voo interior, de abraçar minha história como seiva de nutrição e realização. Também é tempo de descansar, alçando novos projetos mais pessoais, como a pintura em telas que nunca tive tempo de me dedicar e a leitura mais intensa e frequente de obras literárias.

Quais foram os principais desafios encontrados no início da sua carreira de docente e pesquisadora? Quais eram as questões historiográficas que estavam em voga naquele momento? 
O período de magistério em cursinhos e escolas foi um grande desafio naquela fase da minha vida. Eu estava começando e urgia aprender, na prática, como trabalhar em sala de aula. Nos cursinhos, em especial, chegava a ser engraçado, pois os estudantes tinham praticamente a minha idade, o que gerava alguma confusão na definição das devidas posições. No pré-vestibular, eu era a única mulher do corpo docente e, sendo muito jovem, passei alguns apertos para fazê-los entender que ali eu era tão somente professora. Não foi fácil, mas o aprendizado de definição de lugares e de como me relacionar com alunos valeu muito para o caminho que percorri desde então.

Quando comecei a dar aulas no ensino universitário, na Pontifícia Universidade Católica de Minas Gerais, em 1976, senti enorme realização e orgulho. Eu tinha 24 anos e, para mim, ficou claro que aquela seria a minha vida profissional. Penso que, ao escolher a História e a Ciência Política como áreas dialogais de conhecimento, e ao me dirigir para a carreira acadêmica, fiz as escolhas, a bem dizer, adequadas ao meu gosto pelas Ciências Humanas e Sociais e ao meu temperamento muito expansivo que se combina (graças a Deus) com muita vontade de concentração, silêncio e leituras de diferentes tipos, das literárias às acadêmicas.

Quanto à historiografia, na década de 1970, predominava uma forte influência marxiniana e, portanto, estruturalista. Eram principalmente os ingleses, como Christopher Hill, Edward Thompson e Eric Hobsbawm, quem mais influenciavam uma parte expressiva da comunidade de historiadores. Nessa época, meu gosto pela história política começou a ganhar grande e intensa força. Essa opção desdobrou-se na minha integração à Ciência Política. Foi fabuloso mergulhar em uma bibliografia teórica mais contemporânea, tendo como autores que mais me influenciaram: Antônio Gramsci, Norberto Bobbio, Barrigton Moore Jr, C. B. Macpherson e Max Weber. Foi marcante a leitura da Ética Protestante e o Espírito do Capitalismo, de Weber. Levou-me a ler autores marxistas com um olhar mais arguto, proporcionado por abordagens diferentes das estruturalistas. Uma abordagem mais culturalista ganhava corpo na minha formação. Dela não mais me separei. Muito contribuiu para futuras experiências como a da inserção na metodologia da história oral, anos depois.

O mais curioso foi que caminhei, aparentemente, na mão oposta ao que começava a ganhar projeção, na década de 1980, junto aos historiadores brasileiros: micro história, sensibilidades e história cultural, tudo como rescaldo criativo e positivo 
da Escola dos Annales, fundada por Marc Bloch e Jacques Le Goff e abraçada, em diferentes fases e de distintas maneiras por historiadores como, Lucien Febvre, Fernand Braudel, Marc Ferro, George Duby, Pierre Nora e Jacques Revel. Essa orientação chegou também marcada por um lastro crítico ao positivismo e à história política institucional.

Por opção teórica e metodológica, entretanto, nunca cheguei a escrever história política segundo os moldes positivistas. Estudei, sim, instituições como, partidos políticos e sindicatos, mas sempre em uma perspectiva crítica à História que denominamos "oficial". No fundo, no fundo, sempre quis me dedicar à história social em sua interrelação com a história política. Esses são os fundamentos iniciais e permanentes das minhas opções historiográficas.

Na década de 1970, época em que se graduou, havia uma nítida influência do estruturalismo nas Ciências Humanas. Como a senhora percebe o deslocamento da história estrutural para a história do sujeito e para micro história? E a história do tempo presente?

A História é uma área de conhecimento vastíssima que comporta muitas abordagens, diferentes ângulos temporais e espaciais, escolhas metodológicas e temáticas variadas e uma multiplicidade de interrelações. Para mim, o chão da História, como conhecimento, é formado por: temporalidade, espacialidade, pesquisa e/ou construção de fontes, claras opções metodológica e teórica, muita erudição e capacidade de estabelecer diferentes interrelações. Para esse último ângulo, a teoria da circularidade do italiano Carlo Ginzburg é essencial.

Não gosto de divisões estanques e opções excludentes. No meu entendimento, a título somente de exemplo, é importante e possível pesquisar o cotidiano da vida de trabalhadores, inclusive fora do ambiente de trabalho, nos bairros e lares, relacionandoo com condições estruturais macroeconômicas, do âmbito da história estrutural, bem como mentalidades e cultura, vinculados a um ou outro tipo de estruturalismo.

O homem, como ser individual e coletivo, é o sujeito da História que atua em diferentes conjunturas. Segundo Gramsci, as estruturas se atualizam nas conjunturas pela ação dos sujeitos históricos. Essa teoria é a que abraço com maior conforto. A exclusão de ângulos estruturais ou da micro história, em favorecimento de um ou de outro, não proporciona uma visão holística que entendo ser fundamental na área do 
conhecimento histórico. Pode-se e é importante se escrever monografias, em especial nos primeiros anos de formação, mas a História não é monográfica, nem monotemática. Sua beleza e seu desafio são exatamente o de entendê-la como área múltipla, com fronteiras internas e externas pouco rígidas e permeáveis. Portanto, é fundamental o diálogo com diferentes áreas de conhecimento como Economia, Ciência Política, Ciências Sociais, Ecologia, Literatura, Artes, Ciência e Tecnologia, entre outras.

A coleção Brasil Republicano, de quatro volumes, organizada por Jorge Ferreira da Universidade Federal Fluminense (UFF) e por mim, tem tido expressiva aceitação nas universidades. Cada um desses volumes alcançou várias edições. Atualmente, estamos preparando uma nova reedição e atualização, acrescidas de um quinto volume, sobre o Brasil do tempo presente. Cada livro aborda um período da História do Brasil República e conta com a colaboração de inúmeros historiadores que escrevem sobre: História Política, História Econômica, História da Cultura, História Social, História Militar, História das Relações Internacionais, História do Pensamento Social e Político, entre outros temas e abordagens. Considero que a estrutura e a organização dos capítulos da coleção expressam muito bem a concepção historiográfica interrelacional que abraço.

A valorização da atuação de sujeitos históricos, no caso da minha trajetória profissional, ficou muito bem demarcada quando abracei a opção de trabalhar com história oral. Foram anos consecutivos de trabalho com essa metodologia, entrevistando sujeitos históricos de diferentes inserções. Militantes partidários e sindicais quando vinculada, como coordenadora e pesquisadora ao Núcleo de História Oral da UFMG; posteriormente, entrevistando membros do clero e leigos que atuaram na Igreja Católica nos anos de 1960 a 1990. Nessa fase, já de volta à PUC Minas, na metade dos anos de 1990, participei, como coordenadora e pesquisadora, de projetos de pesquisa sobre o Catolicismo no Brasil Contemporâneo. No ano de 2000, cheguei a ser presidente da Associação Brasileira de História Oral (ABHO) e, em 2006, escrevi o livro intitulado História Oral, memória, tempo e identidades. ${ }^{3}$

\footnotetext{
${ }^{3} \mathrm{O}$ projeto de pesquisa da UFMG que, na sua primeira versão, recebeu o título de Minas Gerais, política e sociedade através da história oral, teve financiamento da FUNDEPE/UFMG, CNPq e da FAPEMIG. Foi executado por uma equipe multidisciplinar (História, Sociologia e Ciência Política). Nessa fase inaugural, contou com a participação dos seguintes pesquisadores: Ligia Maria Leite Pereira, Lucília de Almeida Neves Delgado, Maria Eliza Linhares Borges, Michel Marie Le Ven, Thaís Pimentel e Regina Helena Alves da Silva. Seus acervos e as demais pesquisas que o sucederam estão sob a guarda do Núcleo de História Oral da Faculdade de Filosofia e Ciências Humanas dessa universidade. O projeto desenvolvido na PUC Minas foi interdisciplinar, versou sobre O Catolicismo no Brasil Contemporâneo:
} 
A história oral e a história do tempo presente custaram muito para serem absorvidas por parte expressiva da comunidade de historiadores que entendem ambas como possíveis presas da subjetividade. Criticam a história do tempo presente por estar muito próxima do tempo de vida do historiador e a história oral por vir carregada de experiências pessoais. Para eles, faltam às duas, qualquer possibilidade de alcançarem algum grau de objetividade. De qualquer forma, as resistências diminuíram muito e, hoje, um número expressivo de historiadores dedica-se ao tempo presente, sendo que muitos deles fazem uso da metodologia da história oral.

Quanto à história oral, a presença do historiador ou de outros profissionais de áreas afins é indispensável. São eles que conduzem o processo, desde a definição do projeto de pesquisa, a escolha dos sujeitos históricos que serão entrevistados, a seleção das narrativas a serem destacadas em artigos e livros e a elaboração de interpretações. Dedicar-se à pesquisa com utilização da história oral é muito desafiante, pois o historiador realiza dois tipos de tarefas, produção de fontes e análise crítica das mesmas. No livro História Oral: memória, tempo, identidade (2006), considero que:

\begin{abstract}
A análise do depoimento de história oral, isto é da fonte construída, pode se constituir em experiência ímpar e surpreendente, pela riqueza e diversidade das versões obtidas e muitas vezes pela possível sugestão de interpretações alternativas sobre determinado assunto, bem como o estímulo a novos temas a serem pesquisados.
\end{abstract}

Sobre o tempo presente, em fértil parceria com Marieta Ferreira da UFRJ, organizei o livro História do Tempo Presente (2014), que conta com a colaboração de pesquisadores de diferentes instituições. Na sua apresentação, apontamos que:

\begin{abstract}
A história do tempo presente está na ordem do dia. Depois de tanto tempo sob suspeita, ela enseja hoje uma reflexão epistemológica fundamental para a redefinição do campo teórico e metodológico da História, trazendo consigo a renovação da história política, a ampliação do uso de fontes, novos diálogos com as Ciências Sociais, revalorização de atores coletivos e individuais e rediscussão das relações entre memória e história.
\end{abstract}

Logo após se aposentar como professora da UFMG, a senhora foi contratada pela PUC Minas, onde lecionou no curso de História e, posteriormente, no programa de pós-graduação em Ciências Sociais. Quais foram os principais desafios dessa

da politização dos anos sessenta à espiritualização dos anos noventa. Sua equipe era também interdisciplinar: Amauri Ferreira, Alberto Antoniazzi, Leonardo Carlos, Lucília de Almeida Neves Delgado, Sandra Tosta, Solange Bicalho e Yonne Grossi. Contou com financiamento da própria PUC Minas e da FAPEMIG. Seu acervo está sob a guarda do Centro de Memória e Pesquisa Histórica da PUC Minas. 


\section{mudança, especialmente no diz respeito ao trabalho com os referenciais teóricos da sociologia?}

Minha ida para a PUC Minas aconteceu em um momento muito fértil da minha vida acadêmica, que foi coroada, na UFMG, pelo exercício da função de pró-reitora de graduação no período do mandato do reitor, Thomaz Haroldo da Mota Santos, que era muito diferenciado por ter uma visão de mundo aberta e livre de pré-conceitos. Ser próreitora em uma universidade com o porte e o reconhecimento da UFMG ampliou minha visão do mundo universitário, com suas diversas concepções sobre política educacional, especificidades ideológicas, culturais e demandas de diferentes áreas de conhecimento, incluindo, em uma classificação mais vasta, Artes, Biologia, Saúde, Engenharias, Exatas, Humanas e Sociais. Precisei, como nunca antes em minha vida, olhar o mundo com olhos da pluralidade e, sobretudo, da generosidade e respeito para com as diferenças. Pelos retornos que até hoje recebo, penso que posso considerar que foi uma experiência exitosa, embora muito trabalhosa e cansativa.

Minha primeira experiência no magistério superior foi na PUC Minas, a partir de meados de 1976 até o início de 1978, quando, então, ingressei na UFMG. O tempo em que trabalhei pela primeira vez na PUC foi de muita realização e aprendizado. Dei aulas no ciclo básico de Ciências Sociais, que era coordenado, com especial competência, pelo sempre saudoso e inigualável gestor e humanista convicto, Padre Geraldo Magela Teixeira, reitor que me recebeu quando retornei a essa casa, em 1996.

Sempre gostei da PUC, em especial de seu ambiente universitário. Ser professora de seu curso de graduação em História foi muito prazeroso, embora desafiante, por ser um novo recomeçar. Aliás, minha vida tem sido feita de muitos recomeços. Os colegas do Departamento de História dessa universidade acolheram-me com muito carinho, o que contribuiu para diminuir o desalento que senti ao sair da UFMG, em razão de estar me afastando institucionalmente de muitos colegas queridos da História, da Faculdade de Filosofia, Ciências Humanas e Letras (FAFICH) e de outras faculdades e setores daquela universidade. Na Universidade Federal de Minas Gerais, consolidei minha carreira e tive uma atuação intensa. Sou muito grata pelo tempo em que ali trabalhei.

A fundação da pós-graduação em Ciências Sociais na PUC Minas levou-me a integrar seu corpo docente. Uma vez mais pude comprovar o quanto minha formação em Ciência Política foi essencial à carreira que construí. Do que mais gostei ao ali atuar 
foi poder dar continuidade à orientação de dissertações e teses. Muitos dos estudantes que orientei, tanto na UFMG como na PUC, tornaram-se professores de diferentes universidades, o que muito me orgulha e realiza. Bons exemplos dessa vivência são vocês, hoje professores universitários (PUC Minas e Universidade Federal de São João del Rei - UFSJ) que estão a me entrevistar. Outros alunos que orientei são atuais colegas da UFMG, Universidade Federal Fluminense (UFF), Universidade Federal de Campina Grande (UFCG), Universidade Federal do Rio de Janeiro (UFRJ) e Universidade Federal de Ouro Preto (UFOP). Na PUC Minas, finalmente, fiz concurso, resultado em edital público, para professora titular.

Não poderia deixar de registrar, também, minha vinculação à Universidade de Brasília (UnB), onde, após prestar concurso para a área de Brasil República em 2010, atuei, por cerca de seis anos nos cursos de graduação e pós-graduação em História e ainda continuo atuando, como professora colaboradora, no seu programa de pósgraduação em Direitos Humanos.

Já dizia Maquiavel, nos idos do século XVI, que a vida é marcada pela virtu (habilidades) e pela fortuna, isto é, pelas circunstâncias. Minha vinda para Brasília foi determinada pela fortuna. Coube a mim tentar exercer a virtu para me integrar à cidade e à sua vida acadêmica e social. Meu tempo de UnB não foi tão longo como da UFMG e da PUC Minas, mas foi essencial para meu melhor conhecimento de Brasília e de sua cultura acadêmica, que não deixa de ter especificidades. No curso de História, ministrei disciplinas de Brasil Republicano e de Cultura no Brasil Contemporâneo. Encontrei muitos alunos interessados e comprometidos, alguns dos quais acabei orientando na pós-graduação.

Como desdobramento da minha inserção na UnB, fiz um círculo de amizades que esteve comigo na coordenação do XXIX Simpósio Nacional da Associação Nacional de História (ANPUH), no ano de 2017. Foi uma experiência ímpar, desafiante e muito, muito gratificante. Os corredores da universidade ficaram tomados, durante cinco dias, por milhares de historiadores e estudantes de História das mais diferentes especialidades. Embora com poucos recursos, tivemos uma programação extensa que contou com a participação de historiadores renomados de Brasil, França, México e Argentina. ${ }^{4}$

\footnotetext{
${ }^{4}$ A equipe responsável pela coordenação do XXIX Simpósio Nacional de História foi a seguinte: Lucilia de Almeida Neves Delgado (coordenação), André Honor, Arthur Assis, Diva Gontijo, Léa Carrer, Eloísa
} 
A coordenação do Simpósio Nacional da ANPUH foi decorrência do fato de ter sido, no mandato de 2015 a 2017, vice-presidente dessa associação. Foi o terceiro maior desafio coletivo de minha vida profissional. O primeiro foi a pró-reitoria de graduação da UFMG e o segundo foi a presidência da Associação Brasileira de História Oral (ABHO). A participação na diretoria da Associação Nacional de História foi também, para mim, uma espécie de coroamento da minha carreira. Fico feliz por ter sido um projeto coletivo, pois acredito na força da colaboração e da cooperação acadêmica.

A memória, categoria muito explorada em suas pesquisas, está sendo bastante valorizada atualmente. Instituições públicas, privadas e pessoas estão mais conscientes sobre a importância de se registrar e proteger suas histórias. Paradoxalmente, o "presente contínuo", atributo da pós-modernidade, se coloca como imperativo. Como a senhora percebe as contradições desse cenário?

Penso que exatamente as condições e fundamentos da pós-modernidade, destacando-se a provisoriedade das experiências e vivências, o presente contínuo e a fragmentação, características definidoras do mundo em que estamos inseridos neste novo milênio, levam as pessoas e comunidades a se sentirem "seduzidas pela memória", como bem afirma Andreas Huyssen.

No mundo em que vivemos é muito usual pessoas se sentirem sem chão, sem lastros e com identidades fragilizadas e ameaçadas. A profunda revolução da informática também é um paradoxo em relação à memória, pois, embora o acesso às informações sobre o passado tenha sido facilitado e ampliado, a volatilidade dessas informações também ameaça a permanência dos registros e, portanto, das bases e sentimentos que fundamentam as identidades.

O historiador Júlio Pimentel Filho, da USP, afirma que o passado é tão vasto que dele só conseguimos apreender pequenos vestígios. A insegurança da possível ausência desses restos tem levado pessoas, instituições, organizações sociais a escreverem livros sobre memória e a criarem centros de documentação que denominamos de casas da memória. Essas iniciativas têm proliferado muito mais do que há cinquenta anos. A humanidade não sobrevive sem lastros e raízes.

Barroso, Glauco Feijó, Maria Filomena Coelho, Clauco Feijó, Neuma Brilhante, Susane Oiveira, Ione Oliveira. 
Entendo, todavia, que memória e História são diferentes, embora complementares. Para mim, a memória, é uma fonte importante para a construção do conhecimento histórico. No trabalho, com a metodologia da história oral, essa relação é inevitável. Na verdade, ao recolhermos depoimentos, estamos acionando a memória individual e social do entrevistado para a construção do documento histórico que, como qualquer outra fonte, precisa passar pela crítica documental inerente ao ofício do historiador.

Cabe considerar, também, que a memória, como afirma Jacques Le Goff, é um espaço de disputas infindáveis. Fala-se, por exemplo, de memória dos vencidos, dos vencedores, dos violentados, dos excluídos, dos dominantes. Tudo isso imbuído em conflitos que podem ser étnicos, religiosos, de gênero, políticos e ideológicos, entre outros. No Brasil, a recente iniciativa de criação e atuação da Comissão Nacional da Verdade e as adesões e resistências que foram geradas traduzem, com especial clareza, o que são essas disputas. O historiador, ao analisar a dinâmica das realidades e ao trabalhar com a memória, não pode desconsiderar essa condição de poder e disputa pelo controle em ser guardião do que passou.

Nas últimas décadas, além da maior visibilidade de sujeitos sociais, mulheres, negros, homossexuais, anteriormente relegados pela História, presenciamos sua fragmentação em decorrência da "nova ética das identidades". Pensando nesse horizonte interpretativo que se impõe à historiografia, como a senhora avalia a ausência de grandes projetos coletivos que anteriormente aglutinavam diferentes sujeitos?

A ausência de grandes projetos coletivos, no meu entendimento, está vinculada a vários fatores. Destacam-se as condições da pós-modernidade, em especial a da fragmentação. A questão da identidade continua na ordem do dia, mas as múltiplas identidades, no tempo presente, tornaram-se mais visíveis. Temos identidades de gênero, de nacionalidade - vide nos dias de hoje a questão da Catalunha, entre outras religiosas, sociais e regionais. São várias, muitas vezes sobrepostas, pois nossas identidades são plurais e muitas vezes estão até em conflito. Para não precisarmos ir longe, basta registrar as pregações religiosas fundamentalistas que agridem pessoas, templos e terreiros, onde fiéis realizam seus cultos. 
Nesse mundo complexo, a questão social da desigualdade - embora, em muitos países, cada vez mais aprofundada, não encontra a mesma ressonância das décadas que sucederam à Revolução Russa de 1917 (que completa, neste outubro de 2017, cem anos) quando proliferaram partidos e organizações da sociedade civil que lutavam contra os fundamentos da desigualdade. O socialismo funcionou como antídoto à expansão de um modelo de capitalismo avassalador, selvagem, sem meio termo. Com a queda do mundo socialista e a guinada da China para uma espécie de socialismo híbrido ao capitalismo, as lutas de cunho social perderam força e alento, enquanto as questões identitárias ganharam maior relevo e o capitalismo passou a reinar sozinho.

A emergência de novos sujeitos que ganharam visibilidade na História está inserida na transformação profunda e avassaladora do mundo, fato que também provocou muitas mudanças na historiografia e nos fundamentos da teoria e metodologia da História. São novas questões interpretativas que trazem consigo uma riqueza ímpar de abordagens a serem abraçadas por quem se dedica ao ofício de historiador.

Recentemente, foi relançado seu livro PTB: do getulismo ao reformismo. A conjuntura explorada pela sua pesquisa engloba o período político entre 1945 a 1964 e foi publicada, pela primeira vez, em 1989. De lá para cá, como analisar o cenário atual do ponto de vista político e social do Brasil?

Quando lancei o livro sobre o Partido Trabalhista Brasileiro, no ano de 1989, o Brasil estava, literalmente, fervendo. Aquele foi o ano da primeira eleição presidencial direta pós-1964. Diferentes partidos e candidatos fizeram o que podemos denominar de, "festa da democracia política". Estávamos todos tomados de esperança. Uma esperança construída passo a passo nos anos da transição política e que culminou com a promulgação da Constituição de 1988. Escrever, naqueles anos, minha tese de doutorado, que deu origem ao livro, foi como me integrar ainda mais ao projeto de luta pelo retorno à democracia no Brasil. Penso que foi minha contribuição para o entendimento de outra conjuntura, também eivada de esperanças, que antecedeu 1964. Os governos federais, naqueles anos do pré-1964 no Brasil, construíram, mesmo sofrendo fortes oposições, um projeto desenvolvimentista e nacionalista de combate à desigualdade e, para usar um termo da época, ao subdesenvolvimento. Esse projeto de nação no que diz respeito ao combate às distorções sociais e ao respeito às garantias democráticas foi abortado após o golpe político de 1964. 
Nos dias de hoje, após passarmos por um novo golpe político, que denomino pós-moderno, sentimo-nos invadidos pela desesperança. Vivemos um retrocesso tão extenso e avassalador e estamos engolidos por uma corrupção tão ativa que o cenário futuro é, no mínimo, turvo. Nem como cientista política, a não ser retomando e atualizando o conceito de patrimonialismo e destacando o de individualismo extremo, consigo explicar o que está acontecendo. Além do mais, para minha geração, que dedicou os melhores anos de sua juventude à causa da democracia política e social, viver no Brasil de hoje tem sido um tormento. A palavra é dura, mas é assim que eu e muitos dos meus contemporâneos sentimo-nos.

$\mathrm{Na}$ verdade, pouco quero e consigo falar sobre o Brasil atual e lamento muito o fato de que não verei nosso país retomar os rumos da inclusão social, da transparência (que vinha sendo construída com muito esforço) e da democracia em todas as suas dimensões: política, social, econômica e cultural. Não dará tempo! Quem sabe vocês tenham essa sorte. Se tiverem, lembrem-se de mim e de tantos que, como eu, sentem-se estarrecidos e muito sofridos.

\section{Fale sobre seu caminho poético e literário desenvolvido paralelamente à sua carreira acadêmica.}

A literatura sempre fez parte da minha vida. Quando criança, eu era louca por livros. Um dos melhores presentes que recebi naquela época, embora a conta gotas, foi a coleção, Os Melhores Contos de Fadas (russos, franceses, ingleses, dinamarqueses), publicada, no Brasil, pela Editora Melhoramentos. Eu ficava fascinada lendo aquelas histórias de príncipes, princesas, dragões, fadas e bruxas. Também a leitura de Júlio Verne me fez viajar. Os filhos do Capitão Grant fizeram-me cultivar um desejo de conhecer a Patagônia. Só o realizei em parte, mas ainda conhecerei o extremo sul do nosso continente.

$\mathrm{Na}$ adolescência, descobri Jorge Amado de quem li inúmeros títulos. Gostei demais de todos os que li e como seria natural, de Subterrâneos da Liberdade. Mas Tereza Batista Cansada de guerra cativou-me. A literatura de Jorge Amado emocionava-me. Tive uma fase de Jorge Amado que me levou a esgotar quase todos os títulos do autor.

Em seguida, a literatura russa bateu às minhas portas. Foi um deleite e um desafio. Em primeiro lugar pelas mãos de Máximo Gorki. Seu livro, A Mãe, tocou tanto 
meu jovem coração de quatorze anos que, à época, ganhei uma cadelinha que batizei de Sancheca, em homenagem à personagem do livro Sachenka. Na sequência, chegaram outros russos que me contagiaram ainda mais. De Dostoievski, para mim, o maior de todos os autores russos, li, inicialmente, Crime e Castigo. Arrebatou minha alma. Marcou-me a ferro. Um deslumbramento. Por coincidência, exatamente no dia de hoje, depois de tantos e tantos anos, comecei a relê-lo e volto a ficar encantada.

Pelas bordas iam chegando outros brasileiros. Entre eles, Machado de Assis e Lima Barreto. Com eles, visitei o Rio de Janeiro da Primeira República. Machado de Assis é, para mim, um gênio, com sua fina ironia, escrita elegante e cativante. Li, recentemente, o livro de Silviano Santiago, Machado, que romanceia o último tempo de vida de Machado de Assis. Por vias transversas, reencontrei o grande escritor que muito ocupou minhas horas de leitura. Fiquei feliz ao saber que Santiago foi agraciado com o prêmio Jabuti de 2017, na categoria romance.

No tempo da faculdade, dediquei-me, de forma intensa, aos autores latinoamericanos, à exceção de Borges, que veio bem depois e com força imbatível, juntamente com Octávio Paz. Os autores latino-americanos chegaram em boa hora e com força infinita. Com Gabriel García Márquez, Mario Vargas Llosa, Ernesto Sábato e, mais adiante, Isabel Allende, descobri o realismo fantástico que faz únicos em extensão, criatividade e profundidade os escritos dos autores da América Latina.

Essa introdução, para não me alongar nos meus caminhos de recordação literária, foi escrita tão somente para registrar que a poesia chegou a mim muito tardiamente. Os romances eram os meus preferidos e foi pela sua leitura que descobri a sonoridade das palavras e das construções literárias. Mas só soube disso após escrever meus primeiros versos. Não aqueles da adolescência, que são parte da minha história, contudo, impublicáveis. Refiro-me aos meus poemas que datam do último ano do século passado e do início deste milênio. Três poetas, todos de língua portuguesa e considerados clássicos, fizeram-me mergulhar no mundo da poesia e ler outros autores: Cecília Meirelles, Carlos Drummond de Andrade e Fernando Pessoa. Na sequência, vieram Pablo Neruda e Federico García Lorca. Passando também por Vinicius de Morais, Paulo Leminski e com especial voracidade pela portuguesa Sophia Andresen. Mais recentemente, tenho lido também o português Herberto Helder, que tem a alma profunda e inquieta. Finalmente, é preciso registrar, de forma especial, a prosa poética 
do meu conterrâneo Bartolomeu Campos de Queiroz, que expressa uma sensibilidade especialíssima.

Cada vez mais fui me aprofundando na literatura em paralelo às leituras sobre História e memória. Aliás, a memória é inspiração presente em todos os meus três livros de poesia: Jardim do Tempo (1999), Amor e Asas (2003) e Noites Solares (2014). Finalmente, o fato de ter feito longa psicanálise foi fundamental para que minhas emoções mais profundas aflorassem e para que eu as transformasse em versos.

Encerro com o poema do meu livro, Noites Solares, que muito diz sobre a minha vida e a respeito da minha trajetória como mulher.

\section{SER}

A mulher que sou
Contempla
Desassossega
Silencia
Sossega
Espera
Cantarola
Ri
Voa

As mulheres que poderia ter sido

Visitam-me a instigar-me.

$$
\begin{gathered}
\text { A mulher que sou } \\
\text { Reúne acasos } \\
\text { Chegadas } \\
\text { Caminhos } \\
\text { Inquietude } \\
\text { Desencontros } \\
\text { Juventude } \\
\text { Maturidade }
\end{gathered}
$$

As mulheres que poderia ter sido

Falam-me de outro viver

$$
\begin{gathered}
\text { A mulher que sou } \\
\text { Tem calma ao escutar } \\
\text { Solenidade ao decifrar } \\
\text { Possibilidades } \\
\text { Ousadia } \\
\text { Transformações } \\
\text { Permanências } \\
\text { Projeções }
\end{gathered}
$$

As mulheres que poderia ter sido Convidam-me a recosturar a vida

$$
\begin{gathered}
\text { A mulher que sou } \\
\text { Perambula } \\
\text { Entristece }
\end{gathered}
$$


Saboreia

Tateia

Mergulha

Adensa

As mulheres que poderia ter sido Incendeiam-me de dúvidas

A mulher que sou
Abriga
Cicatriza
Flutua
Engasga
Soletra
Afirma

As mulheres que poderia ter sido

Visitam-me nas madrugadas

A mulher que sou

Saboreia

Horas solares,

Horas lunares

Desejo de alto pensar

Risada em cascata

Abraços acolhedores

Amor requintado

As mulheres que poderia ter sido

Encontram-me nas esquinas

A mulher que sou Vive

Tranças de muitos fios

Humildade da dúvida

Mistérios dos desafios

Sonhos visionários

Decisões de encruzilhadas

Plenitude das chegadas.

A mulher que sou

Reconhece

Paisagem interior

Escultura do tempo

Fronteiras rasgadas

Objetos do afeto

Vestígios de horas solenes

A mulher que sou

Dialoga com meus possíveis

Senão apaziguada

Saboreia a vida com paladar agridoce 